УДК 159.9

DOI: $10.17223 / 17267080 / 68 / 8$

\title{
О.И. Титова
}

Сибирский юридический институт Министерства внутренних дел

Российской Федерачии (Красноярск, Россия);

Красноярский государственный педагогический университет им. В.П. Астафьева (Красноярск, Россия)

\section{Толерантность к неопеделенности как фактор отношения к деловому взаимодействию в контексте развития общекультурных компетенций студентов вуза}

\begin{abstract}
Выявлено, что студенты-менеджеры с высоким и низким уровнем толерантности к неопределенности различаются в своих предпочтениях видов делового взаимодействия. Студенты, более готовые к деятельности в условиях изменений, менее ориентированы на совместную деятельность в проектных командах. И наоборот, студенты с более сформированными компетенциями командной работы обладают низкой толерантностью к неопределенности и потому менее подготовлены к деятельности в условиях изменений.

Ключевые слова: толерантность к неопределенности; деловое взаимодействие; отночение к деловому взаимодействию; компетентность в деловых отношениях; общекультурные компетенции; обучение менеджеров; конкурениия; деловое партнерство.
\end{abstract}

\section{Введение}

Потребности российского общества, связанные с необходимостью обеспечивать производство конкурентоспособных товаров и услуг, в том числе в сфере высокотехнологичных производств, диктуют спрос на менеджеров, которые могли бы управлять предприятием в условиях постоянной неопределенности экономической ситуации. Способность работать в проектных командах, эффективно взаимодействовать с коллективом, принимать ответственные управленческие и экономические решения - все это лишь малая часть реальных ожиданий общества и предприятий современной экономики, «узаконенных» в Федеральном государственном образовательном стандарте высшего образования в перечне требований к общекультурным компетенциям, которыми должны обладать бакалавры и магистры экономического профиля.

Профессиональная деятельность студентов-менеджеров, к которой они должны быть подготовлены, обучаясь в вузе, в значительной степени предполагает деятельность в условиях неопределенности, обусловленной динамикой развития социально-экономической ситуации в обществе в це- 
лом и на конкретном предприятии в частности, а кроме того - влиянием на нее так называемого человеческого фактора - изменчивости поведения и намерений конкретных людей, с которыми менеджер взаимодействует в ходе решения профессиональных задач. Вместе с тем часть молодых специалистов не готовы к эффективной работе в условиях динамичных рыночных отношений, к изменению профиля своей деятельности при изменившейся стратегии развития предприятия, появляющихся на рынке технологиях, порой они не способны проявлять гибкость мышления в разрешении конкретных ситуаций, прогнозировать их возможные последствия, особенно когда это касается необходимости осуществлять деловое взаимодействие в совместной деятельности.

Таким образом, потребность в выпускниках вузов, умеющих осуществлять деловое взаимодействие в условиях динамично меняющейся социально-экономической ситуации и тем самым развивать инновационные высокотехнологичные предприятия, в обществе есть, а инструментарий для мониторинга сформированности компетенций в сфере делового взаимодействия на этапе вузовской подготовки - в большом дефиците. В силу разных обстоятельств вузами зачастую используется педагогическое тестирование, которое затрагивает в лучшем случае когнитивный компонент компетенций, обеспечивающих готовность выпускника к деловому взаимодействию. Для мониторинга и оценки общекультурных компетенций, относящихся к организации взаимодействия в коллективе, а также взаимодействия с деловыми партнерами в совместных проектах и командной работе, целесообразно задействовать результаты диагностики интегративных характеристик личности студента и его представлений о деловом взаимодействии, проводимой в рамках психологического сопровождения обучающихся в вузе.

Работа современных менеджеров связана с действиями в условиях неопределенности и вероятностных сценариев развития событий. Источником неопределенности может выступать состояние внешней среды организации при прогнозировании и планировании, на которое влияют ситуация в экономике, научно-технические достижения, социокультурные и политические факторы, международные события и др. При принятии решений именно неопределенность является характерным условием работы менеджера, в том числе в силу того, что источниками информации для него часто выступают люди со свойственной им способностью искажать, фальсифицировать ту или иную информацию. Как отмечает в своем диссертационном исследовании И.Н. Леонов, важным условием совместной деятельности в деловых отношениях в связи с этим является способность менеджера к принятию решений в условиях неопределенности [1].

Таким образом, мы полагаем, что одной из ключевых характеристик в структуре личности менеджера выступают толерантность к неопределенности - деловое качество, определяющее деятельность менеджера в изменчивой социально-экономической ситуации, и представления о взаимодействии в деловых отношениях, о партнере, в совокупности своей структури- 
рующие картину мира менеджера, определяющие его установки на принятие решений, выбор конкретных действий в профессиональной деятельности. Следует отметить, что ранее в работе А.А. Грачева и А.И. Кузнецовой изучались представления студентов-экономистов о партнерах по деловому взаимодействию, ими выделены три вида делового взаимодействия - дефицитарное, самореализующее и духовное. Также были изучены представления студентов о партнере по деловому взаимодействию через призму мотивационных характеристик работника, в том числе с учетом периода обучения и половой принадлежности [2, 3]. Авторами отмечается, что представления о коллегах у студентов и специалистов с опытом работы неодинаковы. Так, среди студентов распространен негативно окрашенный образ типичного коллеги (ленив, эгоцентричен в профессиональных интересах, небескорыстен и т.п.), однако к окончанию обучения представления студентов о партнере по деловому взаимодействию становятся менее негативно окрашенными. Исследователи указывают, что в идеале будущий экономист должен владеть всеми видами делового взаимодействия - дефицитарным, самореализующим и духовным, что выступает самостоятельной задачей обучения в вузе.

В работах О.М. Краснорядцевой личностные компетенции студентов-менеджеров анализировались с точки зрения сформированности у них рефлексивных способностей, которые, в свою очередь, автором обозначаются как стержень профессиональной позиции, обеспечивающей успешную профессиональную деятельность выпускника вуза [4]. В ходе изучения социально-психологических индикаторов готовности студенческой молодежи к инновационной деятельности Э.В. Галажинским и О.М. Краснорядцевой был реализован типологический подход, что позволяет продуктивнее осуществлять мониторинг развития актуальных для современного общества личностных компетенций в процессе их формирования на разных этапах обучения в вузе [5].

Поскольку студенты-менеджеры после окончания вуза включаются в уже существующую в обществе, в конкретной организации систему социально-экономических и управленческих отношений, то важными для оценивания их готовности к деловому взаимодействию являются результаты исследования делового партнерства и конкуренции в предпринимательской, управленческой деятельности. Изучая отношение студентов к деловому взаимодействию, мы опирались на методические подходы и результаты теоретико-эмпирических исследований делового партнерства, конкуренции в предпринимательской и управленческой деятельности, реализованных совместно с Т.С. Вавакиной, А.Л. Журавлевым и В.П. Позняковым [6-8]. Рассматривались разновидности делового взаимодействия (конкуренция за экономические ресурсы, конкуренция-соревнование за личные достижения, технико-экономическое партнерство и личностно ориентированное партнерство), принципы и нормы делового партнерства (равенство, взаимность, справедливость, ответственность), иные показатели, характеризующие деловое взаимодействие в совместной деятельности. 
За основу в данном исследовании нами взято определение толерантности к неопределенности как личностной характеристики, выражающейся в способности человека преодолевать неопределенность и тревогу относительно негарантированного и непредсказуемого будущего, готовности принимать неопределенность как норму жизни, творчески преобразовывать окружающую действительность в субъективную определенность, предложенное Е.А. Любачевской [9]. В исследовании М.И. Яновского и В.А. Монастырской анализировалось влияние характеристик личности на принятие решений в условиях неопределенности. Авторами были получены данные о том, что положительно влияют на точность решений в условиях неопределенности такие качества, как персональность, осмысленность, ориентация на процесс [10].

\section{Методы и организация исследования}

В эмпирическом исследовании приняли участие студенты экономических специальностей, обучающиеся на последнем курсе одного из вузов Красноярского края $(\mathrm{N}=64)$. Сбор эмпирических данных осуществлялся в середине 2016-2017 учебного года. Для сбора эмпирических данных использовались методика определения толерантности к неопределенности С. Баднер [11] и опросник, сконструированный нами на предыдущих этапах исследования для изучения делового взаимодействия $[12,13]$. Статистическая обработка данных проводилась с применением $\varphi$-критерия углового преобразования Фишера и процедуры корреляционного анализа в программе MS Excell. Далее представлены результаты, статистическая значимость которых соответствует $\mathrm{p} \leq 0,05$. В данной статье излагаются и обсуждаются результаты сравнительного анализа отношения к деловому взаимодействию у студентов с высокой и низкой толерантностью к неопределенности $(\mathrm{N}=40)$.

\section{Результаты исследования}

Анализ эмпирических данных показал, что половина опрошенных студентов-менеджеров имеют низкий уровень толерантности к неопределенности, что указывает на склонность респондентов данной группы воспринимать необычные и сложные ситуации скорее как угрожающие, чем дающие новые возможности. Недостаток информации или ее двусмысленность доставляют им дискомфорт. Средние значения по шкале толерантности к неопределенности характерны для 32,5\% опрошенных. Высокий уровень толерантности к неопределенности свойствен 17,5\% респондентов. Такие студенты могут чувствовать себя относительно комфортно даже в ситуации с высоким уровнем изменчивости, способны продуктивно действовать в незнакомой обстановке и при недостатке информации берут на 
себя ответственность, могут принимать решения без долгих сомнений и боязни неудачи, в непривычной ситуации видят возможность развития и проявления своих способностей и навыков.

Также респондентам было предложено определить свои предпочтения по отношению к разным видам конкуренции и делового партнерства, оценить, в какой мере те или иные ресурсы они считают необходимыми для успешного партнерства и конкуренции, какие качества свойственно им проявлять в деловых отношениях и наличие каких качеств у другого субъекта делового взаимодействия делает это взаимодействие успешным, психологически комфортным. В ходе эмпирического исследования выявлен ряд особенностей, которые характеризуют отношение к деловому взаимодействию у студентов с высоким и низким уровнем толерантности.

Так, студенты с высоким уровнем толерантности к неопределенности существенно чаще проявляют высокую степень предпочтения конкуренции за экономические ресурсы (85\%), высокая степень предпочтения конкуренции-соревнования за личные достижения в нашей выборке была абсолютной - 100\% студентов с высокой толерантностью к неопределенности (табл. 1). Партнерские отношений у таких студентов характеризуются средней степенью предпочтения технико-экономического партнерства, основой которого является объединение разного рода экономических и материально-технических ресурсов. Средняя степень предпочтения личностно ориентированного партнерства, основанного на значимости качеств делового партнера, эмоциональных отношениях с ним, сходстве ценностей, свойственна 85\% студентов с высоким уровнем толерантности к неопределенности, а 15\% проявляют низкую степень предпочтения данного вида делового взаимодействия.

Т а бли ц а 1

Частотная оценка предпочтений разных видов делового взаимодействия в группах респондентов с высоким и низким уровнем толерантности к неопределенности, \%

\begin{tabular}{|c|c|c|c|}
\hline \multicolumn{2}{|c|}{ Уровень толерантности } & \multirow[b]{2}{*}{$\begin{array}{c}\text { Высокий уровень } \\
\text { толерантности } \\
\text { к неопределенности }\end{array}$} & \multirow[b]{2}{*}{$\begin{array}{c}\text { Низкий уровень } \\
\text { толерантности } \\
\text { к неопределенности }\end{array}$} \\
\hline $\begin{array}{c}\text { Характер предпочтения } \\
\text { вида делового } \\
\text { взаимодействия }\end{array}$ & $\begin{array}{c}\text { Степень } \\
\text { предпочтения }\end{array}$ & & \\
\hline \multirow{3}{*}{$\begin{array}{l}\text { Конкуренция } \\
\text { за экономические } \\
\text { ресурсы }\end{array}$} & Высокая & 85 & 0 \\
\hline & Средняя & 15 & 75 \\
\hline & Низкая & 0 & 25 \\
\hline \multirow{3}{*}{$\begin{array}{l}\text { Конкуренция- } \\
\text { соревнование } \\
\text { за личные достижения }\end{array}$} & Высокая & 100 & 20 \\
\hline & Средняя & 0 & 65 \\
\hline & Низкая & 0 & 7,5 \\
\hline \multirow{3}{*}{$\begin{array}{l}\text { Технико- } \\
\text { экономическое } \\
\text { партнерство } \\
\end{array}$} & Высокая & 0 & 60 \\
\hline & Средняя & 100 & 35 \\
\hline & Низкая & 0 & 5 \\
\hline \multirow{3}{*}{$\begin{array}{l}\text { Личностно } \\
\text { ориентированное } \\
\text { партнерство }\end{array}$} & Высокая & 0 & 50 \\
\hline & Средняя & 85 & 50 \\
\hline & Низкая & 15 & 0 \\
\hline
\end{tabular}


Среди студентов с низким уровнем толерантности к неопределенности каждый четвертый (25\%) оценил свое предпочтение конкуренции за экономические ресурсы как соответствующее низкой степени, а остальные, основной состав этой подгруппы респондентов (75\%), предпочитают этот вид делового взаимодействия на среднем уровне. Конкуренцию-соревнование за личные достижения студенты с низким уровнем толерантности к неопределенности также в значительной доле случаев предпочитают на среднем уровне (65\%), каждый пятый (20\%) отдает предпочтение этому виду делового взаимодействия в высокой степени, не стремятся к нему 7,5\% студентов с низким уровнем толерантности к неопределенности. В отношении партнерского взаимодействия предпочтения студентов с низким уровнем толерантности к неопределенности характеризуются таким образом: в высокой степени предпочтительным считают технико-экономическое партнерство $60 \%$ респондентов, в средней степени - 35\%, в низкой $5 \%$ респондентов. Субъективные оценки предпочтений студентов с низким уровнем толерантности к неопределенности в отношении личностно ориентированного партнерства распределились в равных пропорциях между высокими и средними баллами - половина из них предпочитает этот вид делового партнерства в высокой степени, половина - в средней.

В качестве факторов / ресурсов, обеспечивающих эффективную конкуренцию, студенты с высоким уровнем толерантности к неопределенности выбирают такие, как экономическая ситуация в обществе (42\%), используемые в работе технологии (29\%) и стабильность и свобода выбора (29\%). Студенты с низким уровнем толерантности считают, что для обеспечения эффективной конкуренции важны репутация вашей деятельности (25\%), товарищеские отношения (30\%) и доверие внутри коллектива $(25 \%)$.

Среди факторов / ресурсов, обеспечивающих эффективные партнерские отношения, студенты с высоким уровнем толерантности к неопределенности высоко оценивают такие, как экономическая ситуация в обществе $(42,85 \%)$, репутация вашей деятельности $(57,1 \%)$, товарищеские отношения $(71,4 \%)$, материально-финансовые возможности $(57,1 \%)$. Нейтральную оценку получил фактор «доверие внутри коллектива» $(14,3 \%)$.

Студенты с низким уровнем толерантности к неопределенности для обеспечения эффективных партнерских отношений высоко оценили такие факторы, как «материально-финансовые возможности» (80\%), «товарищеские отношения» $(75 \%)$, «экономическая ситуация в обществе» $(50 \%)$. Как препятствующие эффективному партнерству студентами этой подгруппы охарактеризованы «стабильность и свобода выбора», «техническое оснащение», «используемые в работе технологии». Нейтрально оценили значимость фактора «используемые в работе технологии» $30 \%$ опрошенных студентов с низким уровнем толерантности к неопределенности, «доверие внутри коллектива» $-70 \%$.

В деловом взаимодействии с партнерами студенты с низким уровнем толерантности к неопределенности ориентируются на принципы взаимности (35\%), нравственности (30\%) и справедливости (25\%). Студенты с высоким 
уровнем толерантности к неопределенности в отношениях с партнерами ориентируются на прагматичность $(42,85 \%)$ и равенство $(42,85 \%)$ (табл. 2$)$.

Т а бли и а 2

Принципы взаимодействия, на которые ориентируются студенты с разным уровнем толерантности к неопределенности в отношениях с партнерами, \%

\begin{tabular}{|l|c|c|c|c|c|}
\hline & $\begin{array}{c}\text { Прагма- } \\
\text { тичность }\end{array}$ & $\begin{array}{c}\text { Взаим- } \\
\text { ность }\end{array}$ & $\begin{array}{c}\text { Справед- } \\
\text { ливость }\end{array}$ & Равенство & $\begin{array}{c}\text { Нравствен- } \\
\text { ность }\end{array}$ \\
\hline $\begin{array}{l}\text { Студенты с высоким } \\
\text { уровнем толерантности } \\
\text { к неопределенности }\end{array}$ & 42,85 & 8 & 14,3 & 42,85 & 6 \\
\hline $\begin{array}{l}\text { Студенты с низким } \\
\text { уровнем толерантности } \\
\text { к неопределенности }\end{array}$ & 8 & 35 & 25 & 10 & 30 \\
\hline
\end{tabular}

Также отметим, что в отношениях с партнерами студенты с высоким уровнем толерантности к неопределенности очень часто применяют манипуляции $(85,7 \%)$, часто влияют на партнера $(71,4 \%)$ и время от времени следуют правилу «доверяй, но проверяй» (71,4\%). Студенты с низким уровнем толерантности к неопределенности весьма часто уверены в своем партнере (80\% оценок респондентов), столько же студентов полностью доверяют партнеру.

В завершении эмпирического исследования нами был проведен корреляционный анализ с целью изучения взаимосвязи толерантности к неопределенности и личностных характеристик, проявляемых студентамиреспондентами в деловых отношениях. Личностные характеристики в совокупности образуют соответствующие гендерные типы: маскулинный, фемининный и гендерно-нейтральный.

Т а бли ц а 3

Корреляционные связи гендерно-типологических характеристик студентов с уровнем толерантности к неопределенности и видами делового взаимодействия

\begin{tabular}{|l|c|c|c|}
\hline & $\begin{array}{c}\text { Маскулинные } \\
\text { качества }\end{array}$ & $\begin{array}{c}\text { Фемининные } \\
\text { качества }\end{array}$ & $\begin{array}{c}\text { Гендерно- } \\
\text { нейтральные качества }\end{array}$ \\
\hline $\begin{array}{l}\text { Толерантность } \\
\text { к неопределенности }\end{array}$ & $-0,63 *$ & 0,49 & $0,57^{*}$ \\
\hline $\begin{array}{l}\text { Конкуренция за } \\
\text { экономические ресурсы }\end{array}$ & $0,7 * *$ & $-0,54^{*}$ & $-0,55^{*}$ \\
\hline $\begin{array}{l}\text { Конкуренция- } \\
\text { соревнование } \\
\text { за личные достижения }\end{array}$ & $0,77^{* *}$ & $-0,55^{*}$ & $-0,55^{*}$ \\
\hline $\begin{array}{l}\text { Технико-экономическое } \\
\text { партнерство }\end{array}$ & $-0,49$ & 0,47 & 0,34 \\
\hline $\begin{array}{l}\text { Личностно } \\
\text { ориентированное } \\
\text { партнерство }\end{array}$ & $-0,59$ & $0,54 *$ & 0,38 \\
\hline
\end{tabular}

\footnotetext{
* уровень значимости $\mathrm{p} \leq 0,05$.
} 
В результате корреляционного анализа (табл. 3) выявлены следующие взаимосвязи между изучаемыми характеристиками: при высоком уровне толерантности к неопределенности (напомним, что шкала толерантности к неопределенности имеет обратный порядок значений) респондентам свойственно проявлять в деловых отношениях маскулинные качества, такие как активность, уверенность в себе, независимость, доминантность, авторитарность и др. $(r=-0,63)$; студенты с низким уровнем толерантности к неопределенности, наоборот, не склонны проявлять в деловых отношениях маскулинные качества, а отдают предпочтение гендернонейтральным, таким как тактичность, восприимчивость, систематичность, аналитичность, сознательность и др. ( $\mathrm{r}=0,57)$. Соответствие проявляемых студентами в деловых отношениях качеств тому или иному гендерному типу взаимосвязано, в свою очередь, с их предпочтениями видов делового взаимодействия следующим образом. Высокие оценки предпочтения видов конкуренции (конкуренция за экономические ресурсы, конкуренциясоревнование за личные достижения) в значительной степени взаимосвязаны с проявлением респондентами маскулинных качеств в деловых отношениях ( $\mathrm{r}=0,7$ и $\mathrm{r}=0,77$ соответственно). В то же время выраженные предпочтения личностно ориентированного партнерства высоко коррелируют с проявлением в деловых отношениях качеств, которые соответствуют фемининному типу $(\mathrm{r}=0,54)$.

\section{Обсуждение результатов и выводы}

В заключение подведем итоги и обозначим основные результаты в контексте обсуждаемой проблематики. Во-первых, отметим, что значительная доля респондентов - половина опрошенных студентов выпускного курса - характеризуется низкой толерантностью к неопределенности, что позволяет говорить о недостаточной подготовленности будущих менеджеров к профессиональной деятельности в изменчивых условиях современного общества. Вместе с тем отметим, что с учетом реалий современного общества целесообразно рассматривать высокую толерантность к неопределенности как признак готовности личности к жизнедеятельности в мире изменений не только применительно к будущим менеджерам; задача быть готовым жить и работать в условиях изменений сегодня актуальна для специалистов любого профиля деятельности.

В ходе эмпирического исследования нами выявлено, что студенты с высокой толерантностью к неопределенности в большей мере предпочитают конкурентное взаимодействие, нежели партнерское, при этом конкуренциясоревнование за личные достижения привлекает их более, чем конкуренция за экономические ресурсы. Студенты с низкой толерантностью к неопределенности демонстрируют большее предпочтение партнерскому взаимодействию, чем конкурентному, а технико-экономическому партнерству более, чем личностно ориентированному. В качестве личностных факторов, определяющих эффективность конкуренции, респонденты с низкой толерантностью к не- 
определенности указывают такие, которые основаны на взаимоотношениях: репутация, доверие, товарищеские отношения. В партнерском взаимодействии респонденты с высокой толерантностью к неопределенности ориентируются на прагматичность и равенство; респонденты с низкой толерантностью к неопределенности - на взаимность, нравственность и справедливость.

При сопоставлении результатов эмпирического изучения представлений студентов-менеджеров о деловом взаимодействии, их предпочтений тех или иных его форматов, ориентаций на конкретные принципы в отношениях с деловыми партнерами в совместной профессиональной деятельности и требований к общекультурным компетенциям выпускников экономического профиля обнаруживается следующее противоречие в оценке образовательных результатов: у студентов с высокой толерантностью к неопределенности, т.е. более готовых к жизнедеятельности в условиях изменений, оказываются в меньшей степени сформированными общекультурные компетенции, связанные с совместной деятельностью в коллективе, проектных командах и т.п., поскольку эта категория студентов в значительной степени демонстрирует предпочтение конкурентных отношений и в гораздо меньшей степени ориентирована на партнерские отношения. И наоборот, выпускники-менеджеры, ориентированные на партнерские отношения в совместной деятельности и в этой части обладающие более сформированными общекультурными компетенциями командной работы, обладают низкой толерантностью к неопределенности и, соответственно, меньшей готовностью к жизни в условиях изменений.

Эта противоречивость образовательных результатов в подготовке будущих менеджеров может быть интерпретирована как следствие тенденции деконструкции профессионального образования, проявляющейся в неспособности выпускников к деятельности по своей специальности без дополнительного образования, что ранее отмечал О.В. Лукьянов в контексте оценки образовательных рисков и обсуждения возможностей управления ими в рамках высшей школы $[14,15]$. В этом случае дополнительное образование как раз и призвано будет расставлять нужные акценты в пользу устранения дефицитов в уровне готовности к изменениям или готовности к партнерским отношениям в коллективе и проектных командах - и делать это в зависимости от конкретных задач, поставленных перед менеджером в его самостоятельной профессиональной деятельности.

На этапе вузовской подготовки указанные нестыковки в развитии общекультурных компетенций, связанных с деловым взаимодействием, у студентов с высокой толерантностью к неопределенности могут быть преодолены за счет организации ролевого и делового взаимодействия на учебных занятиях [16], а также решения специально ориентированных на это задач в рамках производственной практики. В то же время вопрос корректировки низкого уровня толерантности к неопределенности остается открытым - и по морально-нравственным основаниям вмешательства в экзистенциальную сферу личности, и по величине корректировки этой личностной характеристики специальными психотехническими средствами. 


\section{Лuтература}

1. Леонов И.Н. Влияние толерантности к неопределенности на профессионально важные качества руководителя : дис. ...канд. психол. наук. Ижевск, 2015. 256 с.

2. Грачев А.А., Кузнецова А.И. Мотивационные характеристики в представлении о партнере по деловому взаимодействию у студентов-экономистов // Знание. Понимание. Умение. 2014. № 3. С. 269-277.

3. Кузнецова А.И. Представления студентов-экономистов о партнере по деловому взаимодействию // Знание. Понимание. Умение. 2015. № 3. С. 319-327.

4. Краснорядцева О.М. Образовательный опыт развития рефлексии в структуре личностных компетенций студентов, обучающихся менеджменту // Сибирский психологический журнал. 2015. № 58. С. 45-60. DOI: 10.17223/17267080/58/3.

5. Galazhinskiy E.V., Krasnoryadtseva O.M. Typological Characteristics of Innovatively Active Student Youth // Procedia - Social and Behavioral Sciences. 2013. Vol. 86. P. 172-176. DOI: 10.1016/j.sbspro.2013.08.545.

6. Журавлев А.Л., Позняков В.П., Титова О.И. Психологические отношения российских предпринимателей к конкуренции и партнерству: гендерный аспект // Психологические исследования проблем современного российского общества. М., 2013. С. 287310. (Труды Института психологии РАН).

7. Вавакина Т.С., Позняков В.П. Образ делового партнера в представлениях российских предпринимателей // Знание. Понимание. Умение. 2013. № 2. С. 217-224.

8. Позняков В.П., Вавакина Т.С. Психология делового партнерства: теория и эмпирические исследования. М. : ИП РАН, 2016. 320 с.

9. Любачевская Е.А. Толерантность к неопределенности как личностный феномен // Акмеология. 2013. № 3 (47). С. 78-80.

10. Яновский М.И., Монастырская В.А. Факторы эффективности ориентировки в ситуации неопределенности // Институт психологии Российской академии наук. Человек и мир. 2017. № 1. Т. 1. С. 219-230.

11. Солдатова Л.А. Психодиагностика толерантности личности : практическое пособие. М. : Смысл, 2008. 120 с.

12. Титова О.И. Гендерные различия в отношениях российских предпринимателей к конкуренции и партнерству : автореф. дис. ... канд. психол. наук, М., 2007. 26 с.

13. Титова О.И., Трухина Ю.И. Гендерные различия структуры психологического отношения предпринимателей к деловому взаимодействию // Вестник Томского государственного университета. 2014. № 383. С. 196-201.

14. Лукьянов О.В. Проблема идентичности и психическая ригидность в психологической и образовательной практике : дис. ... канд. психол. наук. Томск, 1999. 156 с.

15. Лукьянов О.В. Управление образовательными рисками - актуальная социальнопсихологическая практика // Сибирский психологический журнал. 2010. № 35. C. $72-76$

16. Сафина Р.Н., Смирнов А.В., Минияров В.М. Ролевое и деловое взаимодействие студентов вуза как механизм формирования личности будущих менеджеров // Известия Самарского научного центра Российской академии наук. 2011. Т. 13. № 2. C. 58-61.

Поступила в редакцию 17.10.2017 г.; принята 26.12.2017 г.

\section{Сведения об авторе:}

ТИТОВА Ольга Ивановна, Сибирский юридический институт Министерства внутренних дел Российской Федерации (Красноярск, Россия); Красноярский государственный педагогический университет им. В.П. Астафьева (Красноярск, Россия). E-mail: 944058@mail.ru 


\section{TOLERANCE TO UNCERTAINTY AS A FACTOR OF THE RELATION TO BUSINESS INTERACTION IN THE CONTEXT OF STUDENTS' COMMON CULTURAL COMPETENCES DEVELOPMENT}

Siberian journal of psychology, 2018, 68, 131-142. DOI: 10.17223/17267080/68/8

Titova Olga I., Siberian Law Institute of the Ministry of Internal Affairs of the Russian Federation (Krasnoyarsk, Russian Federation); Krasnoyarsk State Pedagogical University named after V.P. Astafyev (Krasnoyarsk, Russian Federation). E-mail: 944058@ mail.ru

Keywords: tolerance to uncertainty; relation to business interaction; business interaction; competence of business relations; common cultural competences; managers training; competition; business partnership.

In this paper, we discuss the role of tolerance to uncertainty as a factor of students' readiness for business interaction. The problem is important due to the need of society in future managers with competences that would let them deal effectively in changing conditions of modern world, and interact in collective and design teams. However, young managers are often not ready for effective work in conditions of dynamic economic relations, for changes in their activity when the strategy of an enterprise development changes, for prediction of possible consequences in business interaction.

We present here the results of an empirical research, in which last year students of management took part. We used the method of tolerance to uncertainty determining by S. Badner and an author's questionnaire for business interaction study.

We discovered that the half of respondents have the low level of tolerance to uncertainty. It shows the tendency to take unusual and difficult situations as threatening rather than giving new opportunities. Only $17.5 \%$ of respondents demonstrated the high level of tolerance to uncertainty, which lets them feel relatively comfortable even in situations with high level of changeability.

Comparative analysis showed that the students with high level of tolerance to uncertainty prefer competition to partnership; competition for personal achievements is preferable to competition for economic resources. The students with low level of tolerance to uncertainty demonstrate greater preference for partnership. The respondents with low level of tolerance to uncertainty note reputation, trust and companionship as factors of successful competition. The respondents with high level of tolerance to uncertainty focus on pragmatic and equality, while another group focuses on mutuality, moral and justice.

The correlation analysis demonstrates that the high level of tolerance to uncertainty leads to masculine properties in business relationship, such as activism, self-confidence, independence, dominance. The students with low level of tolerance to uncertainty are inclined to show gender-neutral properties, such as tact, susceptibility, systematicity, analyticity, consciousness.

We discovered a contradiction in educational results of managers training. Those students who are ready to activity in the changing conditions are less able to do collective activities in design teams. On the contrary, students with better created competences of team work have low tolerance to uncertainty and therefore are less prepared for activity in the changing conditions.

\section{References}

1. Leonov, I.N. (2015) Vliyaniye tolerantnosti k neopredelennosti na professional'no vazhnyye kachestva rukovoditelya [Impact of tolerance on uncertainty on the professionally important qualities of the manager]. Psychology Cand. Diss. Izhevsk.

2. Grachev, A.A. \& Kuznetsova, A.I. (2014) Motivational Characteristics in the Perception of Business Partner by Economics Majors. Znaniye. Ponimaniye. Umeniye - Knowledge. Understanding. Skill. 3. pp. 269-277. (In Russian). 
3. Kuznetsova, A.I. (2015) Economics majors' ideas of a partner in business interaction. Znaniye. Ponimaniye. Umeniye - Knowledge. Understanding. Skill. 1. pp. 319-327. (In Russian).

4. Krasnoryadtseva, O.M. (2015) Educational experience of reflection developing in the personal competencies structure of students studying management. Sibirskiy psikhologicheskiy zhurnal - Siberian Journal of Psychology. 58. pp. 45-60. (In Russian). DOI: $10.17223 / 17267080 / 58 / 3$

5. Galazhinskiy, E.V. \& Krasnoryadtseva, O.M. (2013) Typological Characteristics of Innovatively Active Student Youth. Procedia - Social and Behavioral Sciences. 86. pp. 172176. DOI: $10.1016 /$ j.sbspro.2013.08.545

6. Zhuravlev, A.L., Poznyakov, V.P. \& Titova, O.I. (2013) Psikhologicheskiye otnosheniya rossiyskikh predprinimateley k konkurentsii i partnerstvu: gendernyy aspekt [Psychological relations of Russian entrepreneurs to competition and partnership: the gender aspect]. In: Zhuravlev, A.L. \& Sergienko, E.A. (eds) Psikhologicheskiye issledovaniya problem sovremennogo rossiyskogo obshchestva [Psychological Studies of the Problems of Modern Russian Society]. Moscow: Institute of Psychology RAS. pp. 287-310.

7. Vavakina, T.S. \& Poznyakov, V.P. (2013) The image of business partner in Russian entrepreneurs' perceptions. Znaniye. Ponimaniye. Umeniye - Knowledge. Understanding. Skill. 2. pp. 217-224. (In Russian).

8. Poznyakov, V.P. \& Vavakina, T.S. (2016) Psikhologiya delovogo partnerstva: teoriya $i$ empiricheskiye issledovaniya [Psychology of Business Partnership: Theory and Empirical Research]. Moscow: Institute of Psychology RAS.

9. Lyubachevskaya, Ye.A. (2013) Tolerantnost' k neopredelennosti kak lichnostnyy fenomen [Tolerance to uncertainty as a personal phenomenon]. Akmeologiya. 3(47). pp. 78-80.

10. Yanovskiy, M.I. \& Monastyrskaya, V.A. (2017) The efficiency factors of orientation in a situation of uncertainty. Institut psikhologii Rossiyskoy akademii nauk. Chelovek i mir. 1(1). pp. 219-230. (In Russian).

11. Soldatova, L.A. (2008) Psikhodiagnostika tolerantnosti lichnosti [Psychodiagnostics of Personal Tolerance]. Moscow: Smysl.

12. Titova, O.I. (2007) Gendernyye razlichiya $v$ otnosheniyakh rossiyskikh predprinimateley $k$ konkurentsii i partnerstvu [Gender differences in the relations of Russian entrepreneurs to competition and partnership]. Abstract of Psychology Cand. Diss. Moscow.

13. Titova, O.I. \& Trukhina, Yu.I. (2014) Gender differences in the structure of entrepreneur's psychological attitude to business interaction. Vestnik Tomskogo gosudarstvennogo universiteta - Tomsk State University Journal. 383. pp. 196-201. (In Russian). DOI: $10.17223 / 15617793 / 383 / 30$

14. Lukyanov, O.V. (1999) Problema identichnosti i psikhicheskaya rigidnost' v psikhologicheskoy $i$ obrazovatel'noy praktike [The problem of identity and mental rigidity in psychological and educational practice]. Psychology Cand. Diss. Tomsk.

15. Lukyanov, O.V. (2010) Management in educational risks - actual sociological and psychological practice. Sibirskiy psikhologicheskiy zhurnal - Siberian Journal of Psychology. 35. pp. 72-76. (In Russian).

16. Safina, R.N., Smirnov, A.V. \& Miniyarov, V.M. (2011) Rolevoye i delovoye vzaimodeystviye studentov vuza kak mekhanizm formirovaniya lichnosti budushchikh menedzherov [Role-based and business interaction of university students as a mechanism for forming the personality of future managers]. Izvestiya Samarskogo nauchnogo tsentra Rossiyskoy akademii nauk - Izvestia of Samara Scientific Center of the Russian Academy of Sciences. 13(2). pp. 58-61. 